\title{
ROLE OF RETINOIDS AND THEIR COGNATE NUCLEAR RECEPTORS IN BREAST CANCER CHEMOPREVENTION
}

\author{
Július Brtko \\ Institute of Experimental Endocrinology, Slovak Academy of Sciences, Bratislava, Slovak Republic
}

\section{SUMMARY}

Retinoids are natural and synthetic compounds related to retinoic acid that act through interaction with two basic types of nuclear receptors: retinoic acid receptors (RARa, RAR $\beta$ and $R A R Y$ ) and retinoid $X$ receptors (RXRa, RXR $\beta$ and RXRY) as ligand-activated, DNA-binding, transacting, transcription-modulating proteins involved in a general molecular mechanism responsible for transcriptional responses in target genes. Function of retinoids in organisms affecting broad spectrum of various biochemical and molecular biology reactions is unimaginable without fully functional nuclear receptors - retinoid inducible transcription factors. Retinoic acids exert tumour-suppressive activity due to their antiproliferative and apoptosis-inducing effects. A number of novel retinoids and rexinoids acting through cognate nuclear receptors have been tested both in vitro and in vivo, using cell culture or animal models for breast cancer.

This article briefly summarizes the role and properties of nuclear retinoid/rexinoid receptors as well as selected effects of retinoic acids or selected synthetic retinoids and rexinoids with respect to their potential use in chemoprevention of breast cancer.

Key words: retinoids, rexinoids, nuclear retinoid acid receptors, prevention of breast cancer, regulation of gene transcription

Address for correspondence: J. Brtko, Institute of Experimental Endocrinology, Slovak Academy of Sciences, Vlárska 3, 83306 Bratislava, Slovak Republic. E-mail: julius.brtko@savba.sk

\section{INTRODUCTION}

Breast cancer is still the most common form of cancer death in women in Europe, with 129900 deaths in the year 2004 (1). Chemoprevention, which is defined as the prevention of cancer by pharmacological agents that inhibit or reverse the process of carcinogenesis, has thus increasingly become the focus of breast cancer prevention efforts (2). A number of novel retinoid derivatives, which appear to be of promise based on preclinical and epidemiological data, are at present under investigation. Retinoids comprising vitamin A (retinol), their natural metabolites are involved in the complex arrangements of physiological and developmental responses in many tissues of higher vertebrates that include embryonic development, vision, reproduction, bone formation, haematopoiesis, metabolism, growth and differentiation of a variety of cell types, apoptosis and processes of carcinogenesis. Important carboxyl group containing natural derivatives of retinol include all-trans -, 9-cis - and 13-cis retinoic acids. In higher organisms, all-trans retinoic acid is considered to be the main biologically active form of vitamin A (3).

\section{NUCLEAR RETINOID RECEPTORS}

Discovery of the nuclear receptor superfamily that includes nuclear receptors for steroid and thyroid hormones, retinoids, dihydroxyvitamin $\mathrm{D}_{3}$ and a number of "orphan" nuclear receptors for which ligands are still unknown, was a breakthrough in the field of understanding retinoid mediated mechanism of action in the cell. It is generally accepted that those nuclear receptors represent a superfamily of hormone or other biologically active ligand-inducible transcription factors. The molecules of nuclear retinoid receptors contain several specific domains from which the amino terminal A/B-domain of the nuclear receptor molecule contains a constitutive activation function (AF-1). The central C-domain is a cysteine-rich DNA-binding region consisting of two highly conserved zinc fingers, the D-domain represents a highly flexible structure, and it plays a role as a hinge of the receptor molecule. The carboxy-terminal E-domain is responsible for both retinoid binding and dimerization, and it contains inducible transactivation function (AF-2) $(4,5)$ (Fig. 1). All-trans retinoic

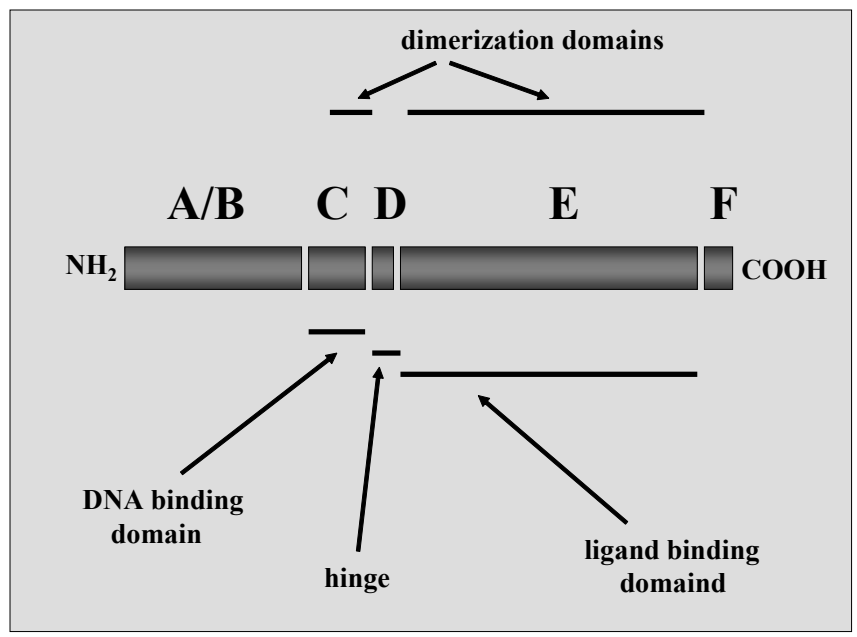

Fig. 1. Simplified scheme of the nuclear receptor basic domains. 


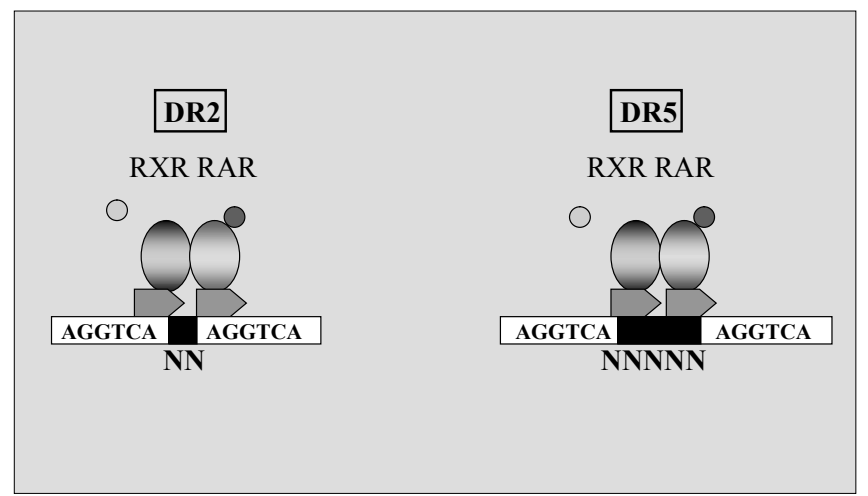

Fig. 2. Retinoic acid response elements (RAREs), characterized by direct repeats of two hexamers AGGTCA separated by either two nucleotides $(D R+2)$ or five nucleotides $(D R+5)$.

acid receptors (RARs) upon all-trans retinoic acid binding act as all-trans retinoic acid-inducible transcription factors by directly interacting as heterodimers with 9-cis retinoic acid receptor (retinoid X receptor, RXR) (6). The RAR/RXR heterodimer interacts with specific DNA response elements of target genes and its effect on transcription is mediated also through recruitment of coregulators (corepressors and coactivators). Ligand occupancy of both receptors in RAR/RXR heterodimers synergistically increases transcriptional activity. Diversity of the retinoic acidinduced signalling pathway is associated with existence of at least three subtypes of RARs (RAR $\alpha, \operatorname{RAR} \beta, \operatorname{RAR} \gamma$ ) and three subtypes of RXRs (RXR $\alpha$, RXR $\beta, \operatorname{RXR} \gamma$ ) with distinct amino- and carboxy-terminal domains. RAR/RXR heterodimers bind to specific DNA sequence - retinoic acid response elements (RAREs), characterized by direct repeats of two hexamers (A/G)GGTCA separated predominantly by five nucleotides $(\mathrm{DR}+5)$ or two nucleotides (DR+2) (7-9) (Fig. 2). In the absence of all-trans retinoic acid, the RAR/RXR heterodimer recruits nuclear receptor corepressor proteins, e.g. nuclear receptor corepressor (N-CoR) or silencing mediator of retinoid and thyroid hormone receptor (SMRT) (10). All-trans retinoic acid binding leads to the dissociation of corepressor proteins and enables association of coactivator proteins with liganded receptor complex yielding in chromatin decondensation and activation of gene transcription.

The retinoids selective for specific binding to RXRs are called rexinoids (11) and RXRs play an crucial role in the nuclear receptor mediated transcription processes for their ability to heterodimerize with many other members of nuclear receptor superfamily, including RARs, thyroid hormone receptors, vitamin $\mathrm{D}_{3}$ receptor, peroxisome proliferator-activated receptor $\gamma(\mathrm{PPAR} \gamma)$, liver $\mathrm{X}$ receptor (LXR) and farnesoid X-activated receptor (FXR) $(12,13)$. RXRs behave as promiscuous dimerization partners for a large number of nuclear receptors, and thus play an integrative and crucial role in nuclear receptor mediated pathways, suggesting that specific RXR ligands (rexinoids) might modulate transcription processes of target genes independently of RARs (14-16).

\section{CHEMOPREVENTION OF BREAST CANCER BY RETINOIDS}

Breast cancer development is associated with deregulation of cell growth and cell death. It has been shown that retinoids are able to inhibit mammary gland cancer in animal models and human breast cancer. They are effective inhibitors of breast cancer cells at the early stages of tumour progression and their effectiveness diminishes as tumours become more aggressive $(17,18)$. 1-methyl-1-nitrosourea (MNU) is a well characterized carcinogen that induces adenocarcinomas in rat mammary gland with high specificity. This model has proven to be of resemblance to human breast cancer and is therefore of great interest for mammary gland tumour studies (19). Our data has shown that among the total number of lesions classified, the percentage of invasive tumours ranged from $35 \%$ to $44 \%$ in female Sprague-Dawley rats treated with MNU. No metastases were observed in other organs in MNU treated animals (20-22).

Recently, we have shown that expression of RAR $\alpha, \operatorname{RXR} \alpha$, thyroid hormone receptor- $\alpha$, both $\alpha$ - and $\beta$-forms of estrogen receptors, nuclear receptor coregulators ( $\mathrm{N}-\mathrm{CoR}, \mathrm{SRC}-1, \mathrm{SMRT})$ and epidermal growth factor receptor (EGFR) in rat was significantly increased in postlactating mammary gland when compared to that of nonlactating mammary tissue. Postlactating mammary glands were found to express all RAR and RXR subtypes studied when compared to nonlactating mammary tissues that express exclusively RAR $\alpha$ and RXR $\alpha$ subtypes. Enhanced expression of a number of nuclear hormone receptors, their coregulators in mammary tissue of postlactating rats in comparison with nonlactating animals identify a potential role for retinoid, thyroid and estrogen signalling pathways also after lactation period (23). Also, a different pattern of expression of retinoid or rexinoid receptors was found in MNU-induced mammary carcinomas in both hypothyroid and hyperthyroid rats (24). In general, retinoids regulate expression of several hundred genes through binding to nuclear transcription factors. Thus, substantial progress has been made in understanding of retinoid metabolism and function (25, 26). 9-cis retinoic acid, a high affinity ligand for RXRs as well as LGD1069 (Targretin, Bexarotene), a synthetic RXR-selective ligand were shown to have efficacy superior to all-trans retinoic acid as a chemopreventive compound in the MNU-induced rat mammary gland carcinoma model. Moreover, Targretin was very well tolerated during chronic therapy with no classic signs of "retinoid-associated" toxicities.

In animal mammary gland carcinoma models, additional promising retinoids are retinyl acetate or N-(4hydroxyphenyl)retinamide (Fenretinide) (27-29). Also, it has been referred that a combination of ligands for peroxisome proliferator-activated receptor- $\gamma$ (PPAR $\gamma$ ) as troglitazone and ligands for RARs and/or RXRs may have a marked therapeutic role for breast cancer (30). The lack of RAR $\beta$ gene expression is a typical feature for human breast cancer and is considered to be one of the major factors responsible for retinoid resistance in those neoplasias. Determination of the expression of all the subtypes of RARs and RXRs in a number of hormone-dependent and hormone-independent breast cancer cells have shown similar expression of RAR $\alpha, \operatorname{RAR} \gamma, \operatorname{RXR} \alpha$ and $\operatorname{RXR} \beta$. However, alltrans retinoic acid was found to be a strong inductor of the RAR $\beta$ gene expression in several hormone-dependent breast cancer cell lines. Due to up-regulation of RAR $\beta$ by all-trans retinoic acid or other retinoids, the expression of RAR $\beta$ apparently plays a critical role in increasing retinoid sensitivity. These data indicate that the deficiency of the RAR $\beta$ expression and a deficient responsiveness of retinoids via RAR $\beta$ may account for the ineffective 
treatment with retinoids in patients with advanced breast tumour (14, 31, 32).

The potency of retinoids to inhibit proliferation of breast cancer cells was seen when retinoids were administered either alone or in combination with antiestrogens. In animal models, the synergistic effects in inhibiting the initiation and promotion of mammary gland tumours induced by carcinogens were observed when retinoids were used in combination with ovariectomy or antiestrogens. Tamoxifen and fenretinide combination therapy has been proven to be an active treatment regimen in metastasis breast cancer patients, however, not in estrogen receptor negative metastasis breast cancer or in patients whose disease had progressed on tamoxifen $(14,32)$. Retinoids do not require estrogen receptors for their action, they may affect neoplastic transformation in estrogen-negative cells, in contrast to tamoxifen, whose primary mechanism of action is through estrogen receptors (33). As to RAR $\beta 2$ expression, it seems to be decreased in intraepithelial neoplasias through hypermethylation, since retinoids have been proposed as attractive partners for demethylating agents $(34,35)$. Retinoids acting predominantly through RAR $\beta$ can promote apoptosis in breast cancer cells as well as in other types of neoplasias (36). Relationship between retinoids, which can act as effective cancer chemopreventive agents or potential chemotherapeutic compounds against breast cancer, and the regulation of the processes such as differentiation and apoptosis is very complex and requires identification of new target genes that might be involved in those processes. Recently, we have studied the effect of 13-cis retinoic acid on the gene expression profile of tumour tissue in a MNU-induced mammary gland carcinoma rat model by the use of a commercial cDNA macro array (Atlas rat toxicology array 1.2, Clontech). The results have shown different expression of a number of genes encoding nuclear proteins and proteins involved in vitamin A metabolism in the retinoid treated MNU group versus mock treated MNU group (37).

\section{CONCLUSION}

In spite of a number of important findings achieved recently by many prestigious laboratories, the precise mechanism(s) by which natural or synthetic retinoids or retinoid inhibit breast cancer cell growth has not been completely elucidated. The generation of novel reinoids and rexinoid with receptor subtype selectivity has opened new opportunities for cancer therapy and chemoprevention. These compounds should be restricted to particular malignancies thus increasing the therapeutic benefit. In spite of that progress, there is still an urgent call for novel synthetic retinoids and retinoid with greater retinoid receptor selectivity, reasonable chemopreventive or chemotherapeutic effects and reduced toxicity and side effects (14, 38, and 39).

\section{Acknowledgements}

This work was partly supported by the grants of the NoE Project EC, FOOD-CT-2004-506319 (CASCADE) and VEGA No. 2/5017/5.

\section{REFERENCES}

1. Boyle P, Ferlay J. Cancer incidence and mortality in Europe, 2004. Ann Oncol. 2005 Mar;16(3):481-8.

2. Bao T, Prowell T, Stearns V. Chemoprevention of breast cancer: tamoxifen, raloxifene, and beyond. Am J Ther. 2006 Jul-Aug;13(4):337-48.

3. Lotan R. Retinoids and apoptosis: implication for cancer chemoprevention and therapy. J Natl Cancer Inst. 1995 Nov 15;87(22):1655-7.

4. Hinds TS, West WL, Knight EM. Carotenoids and retinoids: a review of research, clinical, and public health applications. J Clin Pharmacol. 1997 Jul;37(7):551-8.

5. Nagpal S, Friant S, Nakshatri H, Chambon P. RARs and RXRs: evidence for two autonomous transactivation functions (AF-1 and AF-2) and heterodimerization in vivo. EMBO J. 1993 Jun;12(6):2349-60.

6. Mader S, Leroy P, Chen JY, Chambon P. Multiple parameters control the selectivity of nuclear receptors for their response elements. Selectivity and promiscuity in response element recognition by retinoic acid receptors and retinoid X receptors. J Biol Chem. 1993 Jan 5;268(1):591-600.

7. Chambon P. A decade of molecular biology of retinoic acid receptors. FASEB J. 1996 Jul;10(9):940-54.

8. Crowe DL. Receptor selective synthetic retinoids as potential cancer chemotherapy agents. Curr Cancer Drug Targets. 2002 Mar;2(1):7786.

9. Sun SY, Lotan R. Retinoids and their receptors in cancer development and chemoprevention. Crit Rev Oncol Hematol. 2002 Jan;41(1):41-55.

10. Freedman LP. Increasing the complexity of coactivation in nuclear receptor signaling. Cell. 1999 Apr 2;97(1):5-8.

11. Mukherjee R, Davies PJ, Crombie DL, Bischoff ED, Cesario RM, Jow $\mathrm{L}$, et al. Sensitization of diabetic and obese mice to insulin by retinoid X receptor agonists. Nature. 1997 Mar 27;386(6623):407-10.

12. Mangelsdorf DJ, Evans RM. The RXR heterodimers and orphan receptors. Cell. 1995 Dec 15;83(6):841-50.

13. Willy PJ, Mangelsdorf DJ. Nuclear orphan receptors: the search for novel ligands and signaling pathways. In: O’Malley BW, editor. Hormones and Signaling, Vol. 1. San Diego: Academic Press; 1998. p. 307-58.

14. Brtko J, Thalhamer J. Renaissance of the biologically active vitamin A derivatives: established and novel directed therapies for cancer and chemoprevention. Curr Pharm Des. 2003;9(25):2067-77.

15. Chambon $P$. The nuclear receptor superfamily: a personal retrospect on the first two decades. Mol Endocrinol. 2005 Jun;19(6):1418-28.

16. Sporn MB, Suh N. Chemoprevention of cancer. Carcinogenesis. 2000 Mar;21(3):525-30.

17. Marth C, Bock G, Daxenbichler G. Effect of 4-hydroxyphenylretinamide and retinoic acid on proliferation and cell cycle of cultured human breast cancer cells. J Natl Cancer Inst. 1985 Nov;75(5):871-5.

18. Fontana JA, Mezu AB, Copper BN, Miranda D. Retinoid modulation of estradiol-stimulated growth and of protein synthesis and secretion in human breast carcinoma cells. Cancer Res. 1990 Apr 1;50(7):1997-2002.

19. Mehta RG. Experimental basis for the prevention of breast cancer. Eur J Cancer. 2000 Jun;36(10):1275-82.

20. Liska J, Galbavy S, Macejova D, Zlatos J, Brtko J. Histopathology of mammary tumors in female rats treated with 1-methyl-1-nitrosourea. Endocr Regul. 2000 Jun;34(2):91-6.

21. Liska J, Galbavy S, Zlatos J, Macejova D, Micincova M, Brtko J. Mammary tumors in female rats developed after 1-methyl-1nitrosourea treatment. Biologia. 2000;55 Suppl 8:63-7.

22. Macejova D, Dvorcakova M, Weiss R, Scheiblhofer S, Mostbock S, Liska $\mathrm{J}$, et al. Reduction of 1-methyl-1-nitrosourea-insuced mammary gland carcinoma by in vivo application of immunostimulatory CpG motifs in Sprague-Dawley rats. Gen Physiol Biophys. 2001 Dec;20(4):445-8.

23. Macejova D, Baranova M, Liska J, Brtko J. Expression of nuclear hormone receptors, their coregulators and type I iodothyronine 5'-deiodinase gene in mammary tissue of nonlactating and postlactating rats. Life Sci. 2005 Sep 30;77(20):2584-93.

24. Macejova D, Radikova Z, Macho L, Liska J, Brtko J. MNU-induced carcinogenesis of rat mammary gland: effect of thyroid hormone on expression of retinoic acid receptors in tumours of mammary gland. Mol Cell Endocrinol. 2005 Dec 1;244(1-2):47-56. 
25. Blomhoff R, Blomhoff HK. Overview of retinoid metabolism and function. J Neurobiol. 2006 Jun;66 (7):606-30.

26. Hudecova S, Stefanik P, Macejova D, Brtko J, Krizanova O. Retinoic acid increased expression of the $\mathrm{Na}+/ \mathrm{Ca} 2+$ exchanger in the heart and brain. Gen Physiol Biophys. 2004 Dec;23(4):417-22.

27. Gottardis MM, Bischoff ED, Shirley MA, Wagoner MA, Lamph WW, Heyman RA. Chemoprevention of mammary carcinoma by LGD1069 (Targretin): an RXR-selective ligand. Cancer Res. 1996 Dec 15;56(24):5566-70.

28. Wu K, Kim HT, Rodriquez JL, Hilsenbeck SG, Moshin SK, Xu XC, et al. Suppression of mammary tumorigenesis in transgenic mice by the RXR-selective retinoid, LGD1069. Cancer Epidemiol Biomarkers Prev. 2002 May;11(5):467-74.

29. Moon RC, Constantinou AI. Dietary retinoids and carotenoids in rodent models of mammary tumorigenesis. Breast Cancer Res Treat. 1997 NovDec;46(2-3):181-9.

30. Elstner E, Williamson EA, Zang C, Fritz J, Heber D, Fenner M, et al. Novel therapeuric approach: ligands for PPAR $\gamma$ and retinoid receptors induce apoptosis in bcl-2-positive human breast cancer cells. Breast Cancer Res Treat. 2002 Jul;74(2):155-65.

31. Zhang XK, Liu L, Lee MO. Retinoid receptors in human lung and breast cancer. Mutat Res. 1996 Feb 19;350(1):267-77.

32. Zujewski J, Pai L, Wakefield L, Giusti R, Dorr FA, Flanders C, et al. Tamoxifen and fenretinide in women with metastatic breast cancer. Breast Cancer Res Treat. 1999 Oct;57(3):277-83.

33. Singletary E, Lieberman R, Atkinson N, Sneige N, Sahin A, Tolley $\mathrm{S}$, et al. Novel translational model for breast cancer chemoprevention study: accrual to a presurgical intervention with tamoxifen and N-[4-hydroxyphenyl] retinamide. Cancer Epidemiol Biomarkers Prev. 2000 Oct;9(10):1087-90.
34. Sporn MB. Retinoids and demethylating agents - looking for partners. J Natl Cancer Inst. 2000 May 17;92(10):780-1.

35. Widschwendter M, Berger J, Hermann M, Muller HM, Amberger A Zeschnigk M, et al. Methylation and silencing of the retinoic acid receptor- $\beta 2$ gene in breast cancer. J Natl Cancer Inst. 2000 May 17;92(10): 826-32.

36. Lin B, Chen GQ, Xiao D, Kolluri SK, Cao X, Su H, et al. Orphan receptor COUP-TF is required for induction of retinoic acid receptor $\beta$, growth inhibition, and apoptosis by retinoic acid in cancer cells. Mol Cell Biol. 2000 Feb;20(3):957-70

37. Mostbock S, Macejova D, Baranova M, Weiss R, Scheiblhofer S, Verwanger $\mathrm{T}$, et al. Analysis of altered gene expression profiles in retinoic acid or CpG-treated Sprague-Dawley rats with MNU-induced mammary adenocarcinoma by cDNA macro array. Gen Physiol Biophys. 2003 Mar;22(1):129-33.

38. Zanardi S, Serrano D, Argusti A, Barile M, Puntoni M, Decensi A. Clinical trials with retinoids for breast cancer chemoprevention. Endocr Relat Cancer. 2006 Mar;13(1):51-68.

39. Germain P, Chambon P, Eichele G, Evans RM, Lazar MA, Leid M, et al. Retinoic acid receptors (RARs). In: Laudet V, editor. The NC-IUPHAR Compendium on nuclear receptors. The International Union of Basic and Clinical Pharmacology; 2006. p. 128-45.

\section{Reviewer Acknowledgement}

Although authors are not permitted to thank reviewers in their papers the editoral board of the Central European Journal of Public Health would like to express its thanks to tens of our colleagues - expert reviewers, for their invaluable contribution to the quality of our Journal in the year 2006. 